\title{
DEVELOPMENT AND VALIDATION OF SIMPLE, RAPID AND SENSITIVE UV, HPLC AND HPTLC METHODS FOR THE ESTIMATION OF PIRFENIDONE IN TABLET DOSAGE FORM
}

\author{
S. G. THORAT ${ }^{1,2 *}$, S. P. PADMANE ${ }^{1}$, M. R. TAJNE ${ }^{2}$, A. M. ITTADWAR \\ ${ }^{1}$ Department of Pharmaceutical Chemistry, Gurunanak College of Pharmacy, \\ Dixit Nagar, Near CP Foundry, Nari, Nagpur - 440026 (MS) India. \\ ${ }^{2}$ Department of Pharmaceutical Sciences, Rashtrasant Tukadoji Maharaj Nagpur University, Nagpur-440 033 (MS) India
}

\begin{abstract}
UV, HPLC and HPTLC methods were developed and validated for the quantitative determination of Pirfenidone, a novel antifibrotic agent used in idiopathic pulmonary fibrosis. Chromatography was carried out by isocratic technique on reversed phase Eclipse XDB- $\mathrm{C}_{18}$ column $(150 \mathrm{x} 4.6 \mathrm{~mm}, 5 \mu \mathrm{m})$ with mobile phase consisting of phosphate buff: acetonitrile $\left(\mathrm{pH}^{3.5}\right) 72: 28 \mathrm{v} / \mathrm{v}$ at flow rate $1 \mathrm{~mL} / \mathrm{min}$. TLC was carried out by stationary phase precoated Silica Gel $60 \mathrm{~F}_{254}$ TLC Plate using mobile phase Toluene: Methanol, $8: 2 \mathrm{v} / \mathrm{v}$. The UV spectrophotometric determination was performed at $311 \mathrm{~nm}$ using solvent methanol. The proposed methods were validated according to ICH Q2-(R1) guidelines. The linearity range for Pirfenidone was 5-70 $\mu \mathrm{g} / \mathrm{mL}$ for HPLC, 800-1600 ng/spot for HPTLC and $10-60 \mu \mathrm{g} / \mathrm{mL}$ for UV method. These methods were accurate and precise with recoveries in the range of $98.2-102.32$ and relative standard deviation $<2 \%$. The developed methods were successfully applied for determination of Pirfenidone in tablets.
\end{abstract}

Keywords: UV, HPLC, HPTLC, Pirfenidone, anti-fibrotic agent.

\section{INTRODUCTION}

Pirfenidone is a new drug approved for the treatment of rare and generally incurable idiopathic pulmonary fibrosis (IPF). Patients with IPF suffer from shortness of breath, cough and hampered daily physical activities. Treatment for IPF consists of oxygen therapy, pulmonary rehabilitation and lung transplant. Pirfenidone is the only therapeutic agent available for the treatment of IPF $[1,2]$. It was initially approved in Japan and Europe followed by India and USA in 2010 and 2014 respectively. Pirfenidone or 5-methyl-1-phenyl-2-(1H)pyridone (fig. 1) is a small simple heterocyclic molecule with molecular mass of 185.22 and can be administered orally. Literature survey revealed that HPLC and LC-MS/MS methods are reported for determination of Pirfenidone from biological fluids such as plasma, serum and urine [3] but very few methods have been reported for the estimation of Pirfenidone in pharmaceutical dosage form [4]. Oral tablet formulation containing active Pirfenidone equivalent to $200 \mathrm{mg}$ is available in the territorial markets of Japan, Taiwan, Korea and India whereas it is available in capsule formulation in the USA. Assay or monograph for Pirfenidone or its formulation is not available yet in any pharmacopoeia. Recently we have reported a validated stability-indicating high-performance thin-layer chromatographic method for the estimation of Pirfenidone in tablet formulations [5]. It was learned that recently one report has published HPLC method for determination of Pirfenidone in tablet formulations but this method lacked accuracy and hence we are reporting a better assay including UV and HPTLC along with HPLC method for routine quality control of Pirfenidone formulations [6-9].

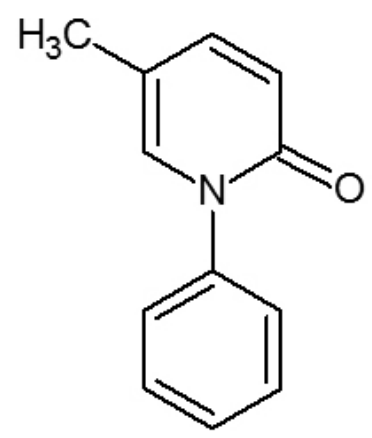

Figure 1. Structure of Pirfenidone.

\section{EXPERIMENTAL}

\section{Chemicals and Materials}

A request sample of Pirfenidone was received from Cipla India Ltd., Mumbai. Methanol AR, acetonitrile HPLC and water HPLC, toluene (AR) grade was purchased from Merck India limited. Film coated tablets of Pirfenidone (Pirfenex, cipla Ltd., Mumbai India) were procured from local market.

\section{Instrumentation}

The chromatographic system comprised of an Agilent 1200 series HPLC system equipped with quaternary gradient pump G1311A with On Line Degasser G1322A. Pre-filtered sample were injected in to Eclipse XDB $\mathrm{C}_{18}$ column $(150 \times 4.6 \mathrm{~mm}, 5 \mu \mathrm{m})$ using Rheodyne syringe loading sample injector (Rheodyne, Cotati, CA). The mobile phase consisted of phosphate bufferacetonitrile $(\mathrm{pH} 3.5)(72: 28 \% \mathrm{v} / \mathrm{v})$. HPTLC instrument consists of CAMAG Linomat-IV TLC applicator, CAMAG TLC-Scanner-III (version 4.0.1) supported with CAMAG Wincats ${ }^{\circledR}$ software (version 4.0.1), CAMAG twin trough glass chamber $(10 \mathrm{~cm} \times 10 \mathrm{~cm})$ for TLC development and Hamilton Syringe $(100 \mu \mathrm{L})$. The mobile phase consisted of toluene- methanol $(8: 2 \mathrm{v} / \mathrm{v})$. A spectrophotometric system consists of a double beam Shimadzu UV/VIS spectrophotometer, UV-1700 having two matched $10 \mathrm{~mm}$ quartz cells with $1 \mathrm{~cm}$ light path equipped with Shimadzu UV probe software was employed in spectrophotometric analysis.

Preparation of standard solution

To prepare standard solution, accurately weighed $100 \mathrm{mg}$ of Pirfenidone was transferred in to $100 \mathrm{~mL}$ volumetric flask, dissolved and diluted up to the mark with methanol to obtain stock solution containing $1.0 \mathrm{mg} / \mathrm{mL}$ of the drug.

Preparation of sample solution

The sample solution was prepared by following method; twenty tablets containing Pirfenidone were accurately weighed and finely powdered. Accurately weighed amount of powder equivalent to $100 \mathrm{mg}$ of Pirfenidone was transferred to $100 \mathrm{~mL}$ volumetric flask and $50 \mathrm{~mL}$ of methanol was added. The mixture was sonicated for $30 \mathrm{~min}$, diluted to mark with methanol and filtered through whattman filter paper no. 41 from the stock solution $1.0 \mathrm{~mL}$ was accurately transferred to $10 \mathrm{~mL}$ volumetric flask and diluted with methanol to obtain an intermediate solution of $100 \mu \mathrm{g} / \mathrm{mL}$ of Pirfenidone. Aliquot of $1.0 \mathrm{~mL}$ of this solution was accurately diluted to $10 \mathrm{~mL}$ with diluents to obtain the final sample solution containing $10 \mu \mathrm{g} / \mathrm{mL}$ of Pirfenidone. This was filtered through $0.45 \mu \mathrm{m}$ nylon filter, degassed by sonication and volume of $20 \mu \mathrm{l}$ was injected in HPLC system. As that same in high performance thin layer chromatography from the stock solution $1.0 \mathrm{~mL}$ was accurately transferred to $10 \mathrm{~mL}$ volumetric flask and diluted with methanol to obtain an intermediate solution of $100 \mu \mathrm{g} / \mathrm{mL}$ of Pirfenidone was applied on HPTLC plate. In UV spectrophotometric sample preparation was same as that of HPTLC from the stock solution $1.0 \mathrm{~mL}$ was accurately transferred to $10 \mathrm{~mL}$ volumetric flask and diluted with methanol to obtain an intermediate solution of $100 \mu \mathrm{g} / \mathrm{mL}$ of Pirfenidone. Aliquot of $1.0 \mathrm{~mL}$ 
of this solution was accurately diluted to $10 \mathrm{~mL}$ with diluents to obtain the final sample solution containing $10 \mu \mathrm{g} / \mathrm{mL}$ of Pirfenidone.

Development of Spectrophotometric and Chromatographic methods

The UV absorption spectrum of Pirfenidone in methanol depicted $\lambda_{\max }$ at $311 \mathrm{~nm}$ and a shoulder peak at $224 \mathrm{~nm}$ (fig.2A). Wavelength showing the maximum absorbance $311 \mathrm{~nm}$ was selected for measurement of absorbance. The HPLC conditions for Pirfenidone was optimal with isocratic mode Phosphate buff: acetonitrile $(\mathrm{pH} 3.5) 72: 28 \mathrm{v} / \mathrm{v}$ at flow rate $1 \mathrm{~mL} / \mathrm{min}$ in a total run time of ten minutes and was used to check the system suitability study. Fig.2B exhibits the corresponding chromatogram of standard Pirfenidone in optimized HPLC conditions showing retardation time for Pirfenidone at $5.56 \mathrm{~min}$. HPTLC was performed on aluminum-backed Silica Gel $60 \mathrm{GF}_{254}$ HPTLC plate from
Merck, India. Sample solution was applied as $6 \mathrm{~mm}$ band and $4 \mathrm{~mm}$ spacing at a constant application rate of $5 \mathrm{sec} \mu \mathrm{l}^{-1}$ by means of Linomat IV sample applicator fitted with a $100-\mu 1$ syringe. The Linear ascending development was performed in a CAMAG twin trough glass chamber with mobile phase consisting of toluene: methanol $(8: 2 \mathrm{v} / \mathrm{v})$. The optimum time for saturation of the chamber with mobile phase vapor was $15 \mathrm{~min}$ at ambient temperature $(25$ $\pm 2{ }^{\circ} \mathrm{C}$ ) and relative humidity $60 \pm 5 \%$. The plates were allowed to develop at distance of $7.0 \mathrm{~cm}$. Subsequent to development; the plates were dried in current of dry air by using compact hot air dryer. Plates were evaluated by densitometry at $315 \mathrm{~nm}$ by means of a CAMAG TLC scanner III with Wincat software version 4.0.1. Figure $2 \mathrm{C}$ displays the corresponding chromatogram of standard Pirfenidone in optimized HPTLC condition.
(A)

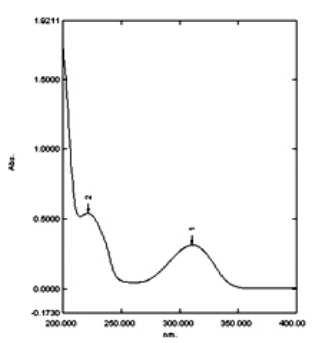

(B)

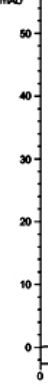

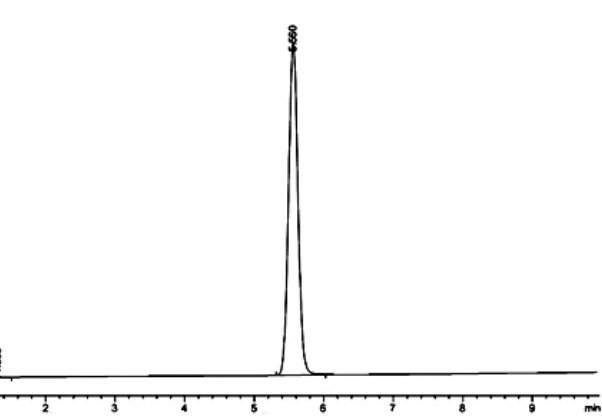

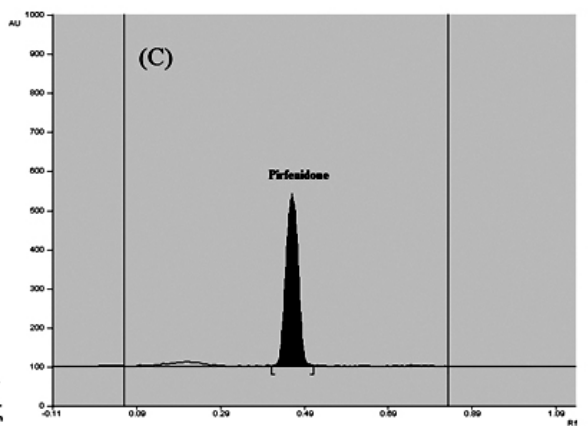

Figure 2. (A) UV spectra of Pirfenidone, (B) Chromatogram of Pirfenidone, (C) Densitogram of Pirfenidone.

Table 1. Validation parameters for determination of Pirfenidone by proposed UV, HPLC and HPTLC methods.

\begin{tabular}{|c|c|}
\hline \multicolumn{2}{|c|}{ Validation of developed methods } \\
\hline Parameters & $\begin{array}{l}\text { UV Spectrophotometric } \\
\text { method }\end{array}$ \\
\hline Linearity range & $10-60 \mu \mathrm{g} / \mathrm{mL}$ \\
\hline Regression equation & $y=0.039 x$ \\
\hline Correlation coefficient & 0.997 \\
\hline Intra- day precision $(\% \mathrm{RSD}, \mathrm{n}=3)$ & 1.02 \\
\hline Inter-day precision (\%RSD, $\mathrm{n}=3$ ) & 1.14 \\
\hline Reproducibility & 1.79 \\
\hline Parameters & HPLC method \\
\hline Retardation time $\pm \mathrm{SD}$ (min) & 5.562 \\
\hline Capacity factor & 2.724 \\
\hline Tailing factor & 1.10 \\
\hline Theoretical plate & 8511 \\
\hline Injection repeatability (\%RSD n=5) & 0.32 \\
\hline Linearity range $(\mu \mathrm{g} / \mathrm{mL})$ & $5-70 \mu \mathrm{g} / \mathrm{mL}$ \\
\hline Regression equation $(\mathrm{y}=\mathrm{mx}+\mathrm{c})$ & $y=43.98 x$ \\
\hline Correlation coefficient & 0.9964 \\
\hline Intra-day precision $(\% \mathrm{RSD} n=3)$ & 0.3701 \\
\hline Inter-day precision (\%RSD n=3) & 0.6751 \\
\hline $\begin{array}{l}\text { Reproducibility (\%RSD, with different } \\
\text { analyst) }\end{array}$ & 2.12 \\
\hline Parameters & HPTLC method \\
\hline Regression equation & $\mathrm{Y}=7223.584+6.598$ \\
\hline
\end{tabular}

\begin{tabular}{|l|l|}
\hline Correlation coefficient & 0.9954 \\
\hline Linearity & $800-1600 \mathrm{ng} / \mathrm{band}$ \\
\hline Precision (intraday) \% RSD & 1.42 \\
\hline Precision (interday) \%RSD & 1.68 \\
\hline LOD & 0.550 \\
\hline LOQ & 1.667 \\
\hline Specificity & Specific \\
\hline Robustness & Method is robust \\
\hline$\%$ Assay & $99.12 \pm 1.28 \%$ \\
\hline $\mathrm{R}_{\mathrm{f}}$ & $0.49 \pm 0.03$ \\
\hline
\end{tabular}

$\mathrm{SD}=$ standard deviation, $\mathrm{RSD}=$ relative standard deviation, $\mathrm{y}=$ concentration of Pirfenidone in $\mu \mathrm{g} / \mathrm{mL}$, $\mathrm{x}=$ peak area of Pirfenidone.

Table 2. Recovery studies for UV, HPLC and HPTLC method.

\begin{tabular}{|c|c|c|c|}
\hline \multicolumn{4}{|c|}{ Recovery Studies } \\
\hline Method & $\begin{array}{l}\text { Amount taken } \\
(\mu \mathrm{g} / \mathrm{mL})\end{array}$ & $\begin{array}{c}\text { Amount added } \\
(\mathrm{mg})\end{array}$ & $\begin{array}{l}\text { \%Recovery } \\
(\text { mean } \pm \text { SD) }\end{array}$ \\
\hline \multirow{3}{*}{ UV } & \multirow{3}{*}{10} & 3.2 & $99.45 \pm 1.10$ \\
\hline & & 7.5 & $98.20 \pm 0.75$ \\
\hline & & 11 & $102.2 \pm 1.62$ \\
\hline \multirow{3}{*}{ HPLC } & \multirow{3}{*}{10} & 3.2 & $101.32 \pm 1.25$ \\
\hline & & 7.5 & $99.15 \pm 0.56$ \\
\hline & & 11 & $99.28 \pm 1.32$ \\
\hline \multirow{3}{*}{ HPTLC } & \multirow{3}{*}{100} & 3.2 & $102.32 \pm 0.55$ \\
\hline & & 7.5 & $100.12 \pm 0.42$ \\
\hline & & 11 & $99.98 \pm 1.44$ \\
\hline
\end{tabular}

Validation of the methods

The proposed methods were validated according to International Conference on Harmonization ICH Q2 (R1) guidelines. The method was 
validated using various parameters such as precision, accuracy, specificity and linearity [9-17]. The system suitability and validation parameters for determination of Pirfenidone by HPLC method are depicted in table 1. Linear correlation was found between peak areas versus concentration of Pirfenidone in the range of $5-70 \mu \mathrm{g} / \mathrm{mL}$ the result of injection repeatability $(\mathrm{RSD}<1 \%)$, intraday and interday precision $(\mathrm{RSD}<1 \%)$ and method reproducibility $(\mathrm{RSD}<2 \%)$ proved the method to be precise. The \% recovery was found to be in the range of 99.15-101.32\% (table 2). The limit of detection (LOD) and limit of quantification (LOQ) was found to be 0.04 and $0.14 \mu \mathrm{g} / \mathrm{mL}$ of Pirfenidone respectively. The specificity of the method was assessed by comparing chromatograms of Pirfenidone obtained from standard solution of drug and that obtained from formulation sample solutions (fig 2). The retardation time of the drug from standard and sample solution was identical. The comparison of chromatograms confirmed that excipients did not interfere in the separation of Pirfenidone. Peak purity check of Pirfenidone peaks obtained from standard solution was found to be 0.9964 , conforming to the specificity of the method. This was further supported by good correlation $(\mathrm{r}=0.996)$ between the PDA spectrum of Pirfenidone from standard solution and that from sample solution of formulation. The change $(\% 5)$ in proportion of organic solvent, the change \pm 2 in wavelength and flow rate did not show significant variation in the area for Pirfenidone $(\% \mathrm{RSD}<2)$. The stability of working standard solution of Pirfenidone was evaluated to verify that any spontaneous degradation occur when the sample were prepared. The stability profile for sample solution of Pirfenidone was studied at different conditions such as normal, acidic, basic, oxide, heat and sunlight. The results were expressed as percentage of drug remaining. The data obtained showed that sample solution was stable during all the conditions with degradation less than $2 \%$ and hence the graphs are not presented.

The validation parameters for determination of Pirfenidone by HPTLC method are depicted in table 1. Linear correlation was found to be in the range of $800-1600 \mathrm{ng} / \mathrm{spot}$ respectively. The result of repeatability $(\mathrm{RSD}<1 \%)$, intraday and interday precision $(\mathrm{RSD}<2 \%)$ and method reproducibility $(\mathrm{RSD}<2 \%)$ proved the method to be precise. The \% recovery was found to be in the range of $99.28-102.32 \%$ (table 2). The specificity of the method was assessed by comparing chromatograms of Pirfenidone obtained from standard solution of drug and that obtained from formulation sample solutions (fig $2 \mathrm{C}$ ). The $\mathrm{R}_{\mathrm{f}}$ value of the drug from standard solution and from sample solution were identical. The comparison of chromatograms confirmed that excipients did not interfere in the separation of Pirfenidone. This was further supported by good correlation $(\mathrm{r}=0.9954)$. The change $(\% 5)$ in proportion of mobile phase and change \pm 2 in wavelength did not show significant variation in the area for Pirfenidone $(\% \mathrm{RSD}<2)$. The stability of working standard solution of Pirfenidone was evaluated to verify that any spontaneous degradation occur when the sample were prepared. The stability profile for sample solution of Pirfenidone was studied at different conditions such as normal, acidic, basic, oxide, heat and sunlight. The results were expressed as percentage of drug remaining. The data obtained showed that sample solution were stable during all the conditions with degradation less than $2 \%$. Validation parameters for determination of Pirfenidone by UV method are depicted in table 1. The Beer's range was found to be in the range of $10-60 \mu \mathrm{g} / \mathrm{mL}$ of Pirfenidone. The result of regression analysis and validation for determination of Pirfenidone by UV method are shown in table 1 . The variability in the precision study was found within limits proving the method to be precise. The \% recovery in accuracy study was found to be $98.20-102.2 \%$ (table 2). The limit of detection (LOD) and (LOQ) was found to be 0.08 and 0.24 , respectively. The working solution of Pirfenidone in methanol was found to be stable for at least five days.

Tablet powder was sonicated with methanol for $30 \mathrm{~min}$ to ensure complete dissolution of drug. The developed UV, HPLC and HPTLC methods were applied to estimate content of Pirfenidone in marketed tablet formulation by our method. The amount of Pirfenidone was calculated using the respective regression equation obtained from calibration graph of UV, HPLC and HPTLC methods. Result of analysis of pharmaceutical formulation containing Pirfenidone is shown in table 3 .

\section{RESULT AND DISCUSSION}

A single report is available on analytical method for determination of Pirfenidone in tablet/capsule formulation with UV and HPLC method [4], other available methods are from the Stability and pharmacokinetic point of view and needed very tedious process such as liquid-liquid extraction and hence are time consuming and non-economical $[5,10]$. The earlier reported HPLC method lacks accuracy with respect to peak sharpness and a single method is reported. We have successfully utilized an isocratic elution technique at room temperature with UV detection for the determination of Pirfenidone in marketed formulation. This method is void of tedious sample preparation procedure and is highly economic. The real advantage of the proposed HPLC method is low retardation time of $5.56 \mathrm{~min}$ for Pirfenidone, this time is higher than the earlier report but presents sharp result. The real advantages of the proposed HPTLC method are high sample throughput with small amount of solvent requirement and simple sample preparation techniques.

Table 3. \% Estimation of Pirfenidone formulation

\begin{tabular}{|c|c|c|c|}
\hline $\begin{array}{c}\text { Dosage } \\
\text { form }\end{array}$ & $\begin{array}{c}\text { Labeled claim } \\
(\mathbf{m g})\end{array}$ & Methods & $\begin{array}{c}\text { \% Content of } \\
\mathbf{d r u g} \pm \mathbf{S D}\end{array}$ \\
\hline \multirow{2}{*}{ Tablet } & \multirow{2}{*}{200} & UV & $101.23 \pm 1.65$ \\
\cline { 3 - 4 } & & HPLC & $99.47 \pm 1.34$ \\
\cline { 2 - 4 } & & HPTLC & $99.23 \pm 0.77$ \\
\hline
\end{tabular}

\section{CONCLUSION}

To conclude with, reported UV, HPLC and HPTLC method for the determination of Pirfenidone in pharmaceutical formulation were found to be highly economical, simple, sensitive, accurate, precise and rapid. Moreover the HPTLC method presented was found to be rather simple and time saving alternative to HPLC method of analysis for Pirfenidone for routine quality control of pharmaceutical formulation.

\section{ACKNOWLEDGMENT}

Authors acknowledge the Cipla Pharmaceuticals Pvt. Ltd for gift sample of Pirfenidone.

\section{REFERENCES}

1. G. W. Hunninghake, A. R. Kalika, J. Respir. Crit. Care Med. 151, 915, (1995).

2. W. J. Depaso, R. H. Winterbauer, Dis. Mon. 37, 61, (1991).

3. C. M. Rubino, S. M. Bhavnani, P. G. Ambrose, Pulmonary Pharmacology \& Therapeutics. 22, 279 (2009)

4. V. K. Parmar, S. B. Desai, T. Vaja, Indian J Pharm Sci. 76, 225 (2014)

5. S. G. Thorat, M. R. Tajne, S. P. Padmane, A. M. Ittadwar, Journal of Planar Chromatography. 28, 398, (2015).

6. Ministry of Health, Labor and Welfare; Report on deliberation results. Nonproprietary Name: Pirfenidone Evaluation and licensing division, Pharmaceutical and food safety Bureau, 2008. Available from: http:// www.pmda.go.

7. CHMP assessment report. International Nonproprietary Name: Pirfenidone Procedure no. EMEA/H/C/002154. European Medicines Agency. 2010. Available from: $\mathrm{http}: / / \mathrm{www} . e m a . e u r o p a . e u$.

8. G. Raghu, H. R. Collard, J. J. Egan, F. J. Martinez, J. Behr, K. K. Brown, Am J Respir Crit Care Med. 183, 788, (2011)

9. http://www.intermune.com/Pirfenidone.

10. S. Tong, $X$. Wang, $H$. Jiang, $X$. Xuegu, Y. Pan, C. Kunming, Chromatographia. 71, 709, (2010).

11. Guidance for industry Food effect bioavailability and fed bioequivalence studies. US Department of Health and Human Services Food and Drug Administration Centre for Drug Evaluation and Research (CDER), December 2002

12. Guidance for industry Bioavailability and Fed bioequivalence studies for orally administered Drug products- General considerations US Department of health and human services Food and Drug Administration Centre for Drug Evaluation and Research (CDER), March 2003.

13. Guidance for industry: Bioanalytical method validation .US Department of Health and Human Services Food and Drug Administration Centre for Drug Evaluation and Research (CDER), Centre for biologics evaluation and Research (CBER), May 2001

14. ICH, Q2 (R1) Validation of Analytical Procedures: Text and Methodology. International Conference on Harmonization of Technical Requirements for Registration of Pharmaceuticals, ICH Harmonized Tripartite guideline November 2005

15. ICH, Q2 (R1) Validation of Analytical Procedures: Text and methodology; In Proceedings of the International Conference on Harmonization; IFPMA, Geneva 2003. 
16. ICH, Q1A (R2) Stability Testing of New Drug Substances and Products; In Proceedings of the International Conference on Harmonization; IFPMA, Geneva 2003.
17. ICH, Q1B. Stability Testing: Photostability Testing of New Drug Substances and Products; In Proceedings of the International Conference on Harmonization. IFPMA, Geneva 2003. 